\title{
Perspective
}

PERSPECTIVE Actualité en histoire de l'art

\section{1 | 2013}

\section{Période moderne/Époque contemporaine}

\section{Choix de publications}

selected readings

\section{(2) OpenEdition \\ 1 Journals}

Édition électronique

URL : http://journals.openedition.org/perspective/2018

DOI : $10.4000 /$ perspective. 2018

ISSN : 2269-7721

Éditeur

Institut national d'histoire de l'art

\section{Édition imprimée}

Date de publication : 30 juin 2013

Pagination : 191-193

ISSN : 1777-7852

\section{Référence électronique}

"Choix de publications », Perspective [En ligne], 1 | 2013, mis en ligne le 11 septembre 2013, consulté le 01 octobre 2020. URL : http://journals.openedition.org/perspective/2018 ; DOI : https://doi.org/ 10.4000/perspective. 2018 


\section{CHOIX DE PUBLICATIONS}

- Mathilde Arnoux, Thomas W. Gaehtgens, Anne Tempelaere-Panzani éd., Correspondance entre Henri Fantin-Latour et Otto Scholderer, 1858-1902, (Passages/ Passagen, 24), Paris, Éditions de la Maison des sciences de l'Homme.

Une amitié constante et sincère a lié, en dépit des tumultes du temps, Henri Fantin-Latour (18361904) et Otto Scholderer (1834-1902), de leur rencontre à Paris en 1857 à leurs décès au début du $\mathrm{xx}^{\mathrm{e}}$ siècle. Le départ du second et ses déplacements fréquents ont suscité une correspondance soutenue, dont plus de trois cents lettres échangées entre 1858 et 1902 sont conservées (celles de Fantin-Latour ne débutant toutefois qu'en 1871). Cette édition soignée et documentée, menée à bien par Mathilde Arnoux, Thomas Gaehtgens et Anne TempelaerPanzani, est destinée à ceux qui ne peuvent faire le voyage jusqu'à l'Institut néerlandais à Paris ou à la Bibliothèque universitaire de Francfort où elles sont conservées. Réalisée sous l'égide du Centre allemand d'histoire de l'art, qui l'a accueillie dans sa collection dédiée aux échanges artistiques franco-allemands, et publiée par la Maison des sciences de l'homme, la publication est accompagnée d'un appareil critique conséquent : trois études replacent la correspondance dans le contexte des relations interpersonnelles, artistiques et internationales, tandis qu'un ensemble d'annexes (biographies croisées, listes des œuvres mentionnées, bibliographie et index des noms et des lieux) en facilitent son usage ; les illustrations, nombreuses, favorisent l'articulation de l'écriture et de la peinture que toute correspondance d'artistes emblématise. À bien des égards, l'ouvrage constitue un objet paradigmatique, par son amplitude exceptionnelle autant que par le point de vue incomparable qu'il offre sur l'état de l'art moderne et les conditions d'exercice du métier d'artiste en Europe du Nord (Fantin-Latour entretenait des liens commerciaux privilégiés avec l'Angleterre tandis que Scholderer alternait les séjours en France, en Allemagne et en Angleterre) à une période décisive, tant pour l'histoire de l'art que pour les relations franco-germaniques. Plus encore, le caractère intime dont ces lettres sont l'expression jette de nouvelles lumières sur l'expérience que les deux amis pouvaient avoir du mouvement dont ils participaient, favorisant l'étude de points de vue " situés " amenant à nuancer, sinon relativiser voire contredire, les simplifications dont toute histoire est faite [F. Desbuissons].

- Thomas W. Gaehtgens, L'Art, l'histoire, l'histoire de l'art, (Passages/Passagen, 39), Paris, Éditions de la Maison des sciences de l'Homme, 2011.

Ce recueil est la traduction d'articles publiés en allemand dans les années 1990 et 2000 .
On y retrouve des thèmes chers à leur auteur et à la collection que ce dernier fonda, dont cet ouvrage est le trente-neuvième volume. À la lecture du sommaire, trois axes se dégagent de ces dixhuit études : la peinture d'histoire, les relations artistiques franco-allemandes et l'institution muséale. Dans les trois champs de recherche, le livre brille par la faculté d'allier l'extrême érudition et l'acuité des questions qui savent aller au détail, et de tirer la leçon d'exemples anodins en apparence, comme ce maladroit portrait équestre de Napoléon par les frères Olivier, où l'auteur sait percevoir l'intention anti-héroïque qui renverse l'effigie du souverain en figure démoniaque. Cette liberté tient aussi à la diversité des périodes et des objets d'études : écrire sur Antoine Watteau ou sur JeanHonoré Fragonard n'interdit pas de s'interroger sur J. J. Grandville, sur Édouard Manet ou encore sur Marsden Hartley, représentant américain des avant-gardes qui permet à l'auteur de revenir sur la dette du cubisme envers les courants spiritualistes et mystiques. Mais le principal apport de cet ouvrage réside peut-être dans son approche de la peinture d'histoire, qui n'est pas envisagée ici comme un genre ou une iconographie, mais sous le rapport des relations très variées que les artistes ont pu entretenir avec les événements qu'ils représentaient, qu'ils en soient les témoins directs, les biographes, les mythographes ou les propagandistes. En abordant successivement les cas de Nicolas Poussin, de Gerard ter Borch, de Benjamin West, de John Trumbull et de Jacques Louis David, le premier article de ce volume démontre avec éloquence à quel point les œuvres d'art ont contribué à forger notre vision de l'histoire, tout en nous livrant des éléments pour comprendre l'interprétation que les commanditaires et les artistes voulaient donner des événements historiques [E. Pernoud].

- Cynthia Gamble, Matthieu Pinette, L'Eil de Ruskin : l'exemple de la Bourgogne, Dijon, Les Presses du Réel, 2011.

Tous les moyens sont bons pour donner vie en français à l'œuvre de Ruskin, continent aussi vaste que labyrinthique qui touche, comme on sait, aussi bien à la peinture et à l'architecture qu'à la théorie du patrimoine et aux arts décoratifs, et qui entrelace toujours esthétique, morale et politique. Parmi les deux livres publiés en 2011 par les Presses du réel, le premier, L'Eil de Ruskin : l'exemple de la Bourgogne, est largement composé d'extraits réunis par Cynthia Gamble et Matthieu Pinette, dans lesquels Ruskin a noté ses impressions bourguignonnes au cours de la quinzaine de séjours qu'il a faits entre 1833 et 1888 dans cette région - à mi-chemin entre ses destinations préférées de la Picardie et de Venise. L'intérêt documentaire est d'autant plus grand que les choix de l'écrivain se portent bien souvent sur 
des villes et des détails - telle fenêtre de maison bourgeoise d'un quartier de Châtillon-sur-Seine, minutieusement analysée et dessinée - à l'écart des grands itinéraires touristiques. Mais, au-delà, c'est le passage incessant du local à l'universel, dans ces notations, qui fait pleinement du livre une entrée à la fois singulière et authentique au cœur du système Ruskin [R. Labrusse].

- Charlotte Jelidi, Fès, la fabrication d'une ville nouvelle, 1912-1956, Lyon, ENS Éditions, 2012.

Dans cette importante contribution à la littérature toujours plus fournie sur l'urbanisme colonial, Charlotte Jelidi examine l'histoire complexe de la création de la nouvelle ville de Fès sous le Protectorat français. S'ouvrant avec les visions ambitieuses de Louis-Hubert Lyautey pour se concentrer sur les années 1930 et 1940 avant de conclure avec quelques incursions dans les années 1950, l'étude de Jelidi adopte une méthodologie interdisciplinaire qui met en avant le rôle des formes construites en tant que documents primaires, les resituant dans des contextes élargis. Elle présente la construction de la ville comme le résultat d'un processus collaboratif qui engage l'administration, les urbanistes, les architectes, les colons européens et l'élite locale, caractérisé par d'innombrables contestations, désaccords, conflits, accointances et négociations entre les différentes parties. Sa lecture attentive des nombreux protagonistes impliqués dans l'entreprise lui permet de présenter un récit nuancé, aux antipodes des constructions binaires simplistes qui opposent clairement le colon et le colonisé. Naturellement, la question politique a son importance et, de fait, "le principe de séparation est respecté jusqu'à la fin du Protectorat " (p. 72). Mais la réalité quotidienne des circonstances sociales, politiques et économiques, ainsi que les conditions géographiques, ont empêché la traduction directe des positions idéologiques dans des schémas urbains grossiers. L'impact des travaux d'aménagement de la médina et des politiques de préservation du patrimoine permet de situer Fès dans son histoire plus large. Les chapitres sur l'architecture, illustrés par des photographies et des dessins soigneusement sélectionnés, rendent la dimension visuelle accessible aux lecteurs. Des recherches méticuleuses ont été menées dans les archives marocaines et dans les Archives nationales, donnant lieu à des ressources abondantes, encore inexploitées pour la plupart. Grâce à sa connaissance approfondie de la littérature sur les villes coloniales (et pas seulement françaises) et à son engagement envers la théorie postcoloniale, Jelidi étaie ses arguments en réponse aux problématiques soulevées par d'autres, et situe son travail dans le champ discursif global [Z. Celik].
- Jorrit Kelder, Günay Uslu, Ömer Faruk ŞERIFOĞLU, Troy: City, Homer, Turkey, Amsterdam, W Books/Allard Pierson Museum, 2012.

Ce recueil d'essais, publié à l'occasion de l'exposition éponyme au Allard Pierson Museum à Amsterdam (7 décembre 2012-5 mai 2013), s'intéresse à la ville légendaire de Troie selon trois angles d'analyse : l'archéologie, la mythologie et réception. À l'aide de photographies et de schémas soignés, les articles de la première catégorie décrivent avec une grande clarté ce site notoirement complexe, composé de neuf strates qui remontent au deuxième millénaire avant Jésus-Christ. Les différentes phases sont examinées chronologiquement, à partir d'artefacts militaires et de la vie quotidienne, et prennent en considération les relations culturelles de Troie avec ses voisins, à savoir les Hittites et les Mycéniens de Grèce. Le groupe d'articles suivant revient sur le passage à l'éternité de la ville que met en œuvre Homère lorsqu'il livre le récit de la guerre de Troie dans L'Iliade et L'Odyssée, et retrace par ailleurs son autorité constante dans la littérature et l'art gréco-romains. L'argument principal étant que « la conception grecque de Troie [...] tirait sa signification de sa propre chute ", un concept qui a perduré à l'époque romaine, au cours de laquelle « la ville est restée invisible ", pour devenir ensuite un lieu de mémoire (p. 82). Les chapitres suivants montrent qu'il en est demeuré ainsi de la période byzantine à sa " renaissance " sous le sultan ottoman Mehmed II (1432-1482), puis dans l'art européen du XVII ${ }^{e}$ siècle, dans L'histoire de Troïlus and Cressida de Shakespeare ainsi que dans divers opéras. La " redécouverte de Troie " par Heinrich Schlieman a ressuscité la ville en des termes concrets, notamment par le biais du " trésor de Priam ». Ce livre apporte des réponses inédites sur la controverse concernant l'appartenance de cette célèbre collection à travers des documents ottomans, et conclut par une assimilation de Homère et de Troie par la culture turque et ottomane. Les essais donnent le jour à un discours nouveau, qui charge les données archéologiques de nouvelles connotations, retrace l'épopée sans fin de la ville mythique à travers les productions artistiques et littéraires, la situe dans un cadre politique et en dit long sur son attrait jamais démenti [Z. Celik].

- John Ruskin, Les Deux Chemins : conférences sur l'art et ses applications à la décoration et à la manufacture, traduit de l'anglais par Frédérique Campbell, Dijon, Les Presses du Réel, 2011 [éd. orig. : The Two Paths, Londres, Smith, Elder \& Co, 1859].

Le système Ruskin (voir ci-dessus, GAMBLE, PinetTe, $2011)$ apparaît à son stade le plus polémique et, ce faisant, aussi le plus influent, à propos de la notion d'art décoratif et de son enseignement, dans Les Deux Chemins. Deux chemins : c'est-à-dire, d'un côté, celui de l'ornement " conventionnel ", venu des peuples non européens et avant tout des 
cultures de l'Islam; de l'autre, celui de la décoration ancrée dans l'étude et la représentation de la nature, magnifié en Occident par les plus grands peintres autant que par les humbles artisans, sans hiérarchie de principe entre eux. Le livre promeut le second et dénonce le premier ; il s'oppose ainsi avec véhémence - quoiqu'implicitement - à la Grammar of Ornament d'Owen Jones, publiée en 1856 et marquée à la fois par une volonté de distinguer radicalement les " lois " de création ornementale de celles des beaux-arts, et par une islamophilie passionnée, à partir des modèles privilégiés de l'Espagne arabo-andalouse et de l'Inde moghole. Le débat est d'autant plus vif qu'en cette fin des années 1850, l'enseignement du "design", comme on l'appelle déjà, est bouleversé par la rapide montée en puissance du South Kensington Museum, à la fois musée, forum d'idées et lieu d'enseignement, avec ses nombreux émules dans les grandes villes industrielles du Royaume-Uni. Dans ce cadre, il est facile - et en partie justifié de dénoncer les prises de position apparemment élitistes et, qui plus est, racistes de Ruskin, qui établit un lien entre ornement non naturaliste et dégradation morale pour vilipender en bloc la "cruauté et la sauvagerie " des cultures non occidentales admirées par Jones. Ces positions, même si elles donnent leur titre au livre, ne sont pourtant pas centrales dans les intentions de Ruskin : ce qui compte pour lui avant tout, fût-ce au prix de sophismes que rehausse l'extraordinaire complication rhétorique de sa phrase, c'est de se situer au cour de la grande question du XIX ${ }^{e}$ siècle : comment transformer la technique en culture ? Question qu'il partage avec Jones et qui fait des Deux Chemins, au même titre que la Grammaire de l'ornement, une admirable caisse de résonance des apories de la pensée de la modernité à l'ère industrielle [R. Labrusse].

\section{RÉSUMÉ}

David Peters Corbett, Peindre les frontières américaines: encounter et les contours de l'identité américaine dans l'art du XIX $X^{e}$ siècle

La perspective historiographique à travers laquelle les chercheurs voient l'Amérique, ainsi que la question incessante de la singularité de la ou des culture(s) de l'Amérique, ont été récemment développées et abordées selon des angles variables par les spécialistes de l'art américain du XIX ${ }^{e}$ siècle. Cet essai s'intéresse à l'idée de la terre, de son occupation et de sa colonisation, au contact avec d'autres cultures, d'autres lieux et d'autres futurs, et se demande comment ces éléments caractéristiques de l'expérience américaine conditionnent le champ discursif au sein duquel les sujets d'étude sont formulés. Les tensions générées par les contacts avec la Frontière et avec l'Autre représenté par la nature et le monde naturel dans la culture américaine du $\mathrm{XIX}^{\mathrm{e}}$ siècle sont examinées, soit l'ensemble des tensions constatées auprès des frontières - aussi bien géographiques qu'imaginaires, intérieures qu'extérieures - des États-Unis au XIX ${ }^{\text {e }}$ siècle. Les travaux des spécialistes révèlent les effets dynamiques et transformatifs de la rencontre avec l'Autre, que ce soit sous forme de paysage ou de changement social, sur l'Amérique du XIX ${ }^{\mathrm{e}}$ siècle.

\section{ABSTRACT \\ David Peters Corbett, Painting American Frontiers: "Encounter and the Borders of American Identity in Nineteenth-Century Art}

The historiographical perspective through which scholars see America, together with the persistent question of the particularity of America's culture(s), have been developed and adapted in varied ways by recent scholars of the art of nineteenth-century America. This essay considers the idea of the land, its settlement and colonization, contact with other cultures, other places, and other futures, and how these central facts of the American experience frame the discourses in which research questions are formulated. The tensions in nineteenth-century American culture generated by contact with the frontier and with the Other represented by nature and the natural world, are considered, tensions generated along the borders - both geographical and imagined, both internal and external - of the nineteenth-century UnitedStates. The encounter with the Other, both in the form of landscape and of social change, is revealed by the scholarly literature as dynamic and transformative in nineteenth-century America. 